\title{
Is peer review in academic publishing still working?
}

Liz Jackson, Michael A. Peters, Leon Benade, Nesta Devine, Sonja Arndt, Daniella Forster, Andrew Gibbons, Elizabeth Grierson, Petar Jandrić, George Lazaroiu, Kirsten Locke, Ramona Mihaila, Georgina Stewart, Marek Tesar, Peter Roberts \& Jānis (John) Ozoliṇš

To cite this article: Liz Jackson, Michael A. Peters, Leon Benade, Nesta Devine, Sonja Arndt, Daniella Forster, Andrew Gibbons, Elizabeth Grierson, Petar Jandrić, George Lazaroiu, Kirsten Locke, Ramona Mihaila, Georgina Stewart, Marek Tesar, Peter Roberts \& Jānis (John) Ozoliņ̌ (2018) Is peer review in academic publishing still working?, Open Review of Educational Research, 5:1, 95-112, DOI: 10.1080/23265507.2018.1479139

To link to this article: https://doi.org/10.1080/23265507.2018.1479139
(c) 2018 The Author(s). Published by Informa UK Limited, trading as Taylor \& Francis Group

曲 Published online: 31 May 2018.

Submit your article to this journal

III Article views: 258

Q View related articles ¿

View Crossmark data $\asymp$ 


\title{
Is peer review in academic publishing still working?*
}

\author{
Liz Jackson ${ }^{a}$, Michael A. Peters ${ }^{b}$, Leon Benade ${ }^{c}, N^{2}$ sta Devine ${ }^{c}$, Sonja Arndt ${ }^{b}$, \\ Daniella Forster ${ }^{d}$, Andrew Gibbons ${ }^{c}$, Elizabeth Grierson ${ }^{\mathrm{e}}$, Petar Jandrić ${ }^{\mathrm{f}}$, \\ George Lazaroiu ${ }^{g, h}$, Kirsten Lockei, Ramona Mihaila ${ }^{j}$, Georgina Stewart ${ }^{c}$ and \\ Marek Tesar ${ }^{\mathrm{i}}$
}

\begin{abstract}
${ }^{\mathrm{a}}$ Faculty of Education, University of Hong Kong, Hong Kong, Hong Kong; ${ }^{\mathrm{b}}$ Faculty of Education, University of Waikato, Hamilton, New Zealand; ' $S$ School of Education, Auckland University of Technology, Auckland, New Zealand; ' $\mathrm{d}$ School of Education, University of Newcastle, Newcastle, Australia; ${ }^{\mathrm{e}} \mathrm{S}$ chool of Art, RMIT University, Melbourne, Australia; ${ }^{f}$ Centre for Research in Digital Education, Zagreb University of Applied Sciences, Zagreb, Croatia; ${ }^{9}$ Institute of Interdisciplinary Studies in Humanities and Social Sciences, New York, NY, USA; ${ }^{\text {SSpiru }}$ Haret University, Bucharest, Romania; 'Faculty of Education and Social Work, University of Auckland, Auckland, New Zealand; ${ }^{\text {}}$ Faculty of Foreign Languages and Literatures, Dimitrie Cantemir Christian University, Bucharest, Romania
\end{abstract}

\section{ABSTRACT}

Peer review is central to academic publishing. Yet for many it is a mysterious and contentious practice, which can cause distress for both reviewers, and those whose work is reviewed. This paper, produced by the Editors' Collective, examines the past and future of peer review in academic publishing. The first sections consider how peer review has been defined and practised in changing academic contexts, and its educational significance in the development of scholarship. The paper then explores major historical and contemporary issues around identity, diversity, anonymity, and the review process, and the related power of editors versus reviewers in academic publishing. Finally, the paper discusses the case of new scholars as reviewers engaging in neoliberal labour, before concluding with some brief recommendations based on our analysis.

\section{ARTICLE HISTORY}

Received 7 November 2017

Accepted 6 March 2018

\section{KEYWORDS}

Peer review; academic publishing; scholarship; neoliberalism; higher education

\section{Introduction}

Peer review occupies a central position in academic publishing yet is seldom acknowledged publicly as a normal part of academic work. In the age of digital reason, it has also become increasingly important for less formal, non-academic 'co-creation and co-production of knowledge, of digital goods in general, and of social democratic processes' (Peters \& Jandrić, 2017). Perhaps unsurprisingly, peer review has become one of the most mysterious and contentious academic practices, causing anguish for many academics-both reviewers, and those whose work is reviewed-and sometimes more

\footnotetext{
CONTACT Liz Jackson lizjackson@hku.hk E University of Hong Kong, Hong Kong 
distress than is necessary. Social and academic media feature a steady parade of articles, blogs, cartoons and memes, telling apocryphal tales of the horrors of peer review.

This paper, produced by the Editors Collective, examines the past and future of peer review of academic publishing. The first sections consider how it has been defined and practised in changing academic contexts, and its educational significance in the development of scholarship. The paper then explores major historical and contemporary issues around identity, diversity, anonymity, and the review process, and the related power of editors versus reviewers in academic publishing. Finally, the paper discusses the case of new scholars as reviewers engaging in neoliberal labour, before concluding with some brief recommendations based on our analysis.

\section{Conceptualising peer review: past and future}

Descriptions and analyses of peer review can be found in two distinct bodies of research: traditional academic research, and insights into logic of peer production developed outside academic settings. Looking at academic research, Fitzpatrick notes:

Very little investigation of the historical development of peer review has been done, and the few explorations that do attempt to present some sense of the system's history largely cite the same handful of brief texts. Moreover, nearly all of the texts exploring the history of peer review focus on the natural and social sciences, and almost none mention peer review in scholarly book publishing. (2011, p. 20)

Non-academic studies are also far from definitive, as they tend to focus on various forms of 'crowd wisdom' and neglect deeper epistemic issues (Jandrić, 2017). In spite of shortcomings in both traditions, it is at the intersections of academic and non-academic settings that we need to build a relevant history of peer review.

Most authors start the discussion about peer review from the first scientific journals such as Henry Oldenburg's Philosophical Transactions, which began publishing in 1776. As the Editors Collective (Peters, Besley, Jandrić, \& Bajić, 2016) notes, however,

It could be argued that the concept of peer review is considerably older than previously thought and that it has its origins in the idea and process of trial by a jury of one's peers. If this connection is historically sound then the notion dates back to fifth Century BCE Ancient Greece ... . In the modern context, the practice apparently evolved from the Germanic tribes and Vikings where the custom was for good men to judge alleged crimes and criminals. In particular, the Vikings used the notion that free men in the court could play a central role. The mediaeval custom was then developed during the reign of Henry II in the twelfth century as a basis for local government that depended on jurors' first-hand knowledge, the forerunner of today's 'expert knowledge,' and original investigation beyond the realm of hearsay and rumour. Magna Carta contains the provision and guarantee that no free man may suffer punishment without 'the lawful judgement of his peers.' Later, the system was reformed with the passing of the Bill for Better Regulation of Juries in 1730.

Peer review clearly predates the production of scholarly journals. It was at the heart of eighteenth-century research practices, such as those of the Royal Society of Edinburgh, who had a system similar to that of Philosophical Transactions in 1731. Fitzpatrick (2011) also notes that while peer review has its origins in state censorship, 'it was intended to augment the authority of a journal's editor rather than assure the quality of a journal's products.' Formalised peer review, she claims, did not become a part of scholarly publishing 
until the mid-twentieth century, when medical journals used outside reviewers to vet manuscripts.

However, Biagioli shows that 'if we take a longue durée perspective, the history of peer review marks a series of changes in the meaning of both "peer" and "review"-changes bordering on role reversals' (2002, p. 32). Contemporary mainstream understanding of peer review stabilised only after strong proliferation of scientific output after World War II (Chapelle, 2014).

At the beginning of the 21st century, traditional science and peer review have embarked on a new set of interconnected transformations. Commodification of science and research has transformed traditional academic publishers into global corporations, and constant mergers have caused significant agglomeration bordering oligopoly-in 2015, five for-profit publishers (Elsevier, Sage, Springer, Taylor \& Francis and Wiley-Blackwell) owned more than half of world's databases of academic material (Barok et al., 2015). Digital transformations have also impacted the mechanics of peer review. Paper-mail has given way to e-mail; now e-mail is being increasingly pushed out of business by online and cloud-based services.

Peer review can be understood today as 'the principle through which science regulates itself through a series of rational judgments and decisions. In this incarnation, peer review is deployed as a powerful discursive tool for the legitimation of science and expertise' (Biagioli, 2002, p. 35). In spite of huge increase in workload, peer review is by and large understood as public service although it serves a private market. While reviewers do not get paid for their highly specialised work, corporate publishers reap huge profit from selling (access to) articles. In the words of Robert Darnton: 'We faculty do the research, write the papers, referee papers by other researchers, serve on editorial boards, all of it for free ... and then we buy back the results of our labour at outrageous prices' (Barok et al., 2015).

\section{The educational value of peer review}

While some regard peer review as an essentially judgmental exercise in humiliation (Comer \& Schwartz, 2014), peer review is more like a form of pedagogy. As a form of pedagogy, peer reviewing is both educational and instructive for both the reviewer and the author. Both are contributing to the process of shaping an article that opens up the field to further conversation and thought while also playing the crucial roles of assessing quality of data and claims. This thinking process could be called a propaedeutic moment, from Greek paideuein, meaning 'to teach' plus 'pro-' meaning 'before'. In this definition peer review activates a form of teaching before something, a continuum towards something, a process of thinking: a processual unfolding towards the final shape of an article for publication.

Questioning is a crucial aspect of the review process, and questioning enhances thinking for all those involved-peer reviewer(s), author(s) and editor(s). As Heidegger shows: 'Questioning builds a way ... . The way is one of thinking' (1999b, p. 311). So through peer review as a propaedeutic process, a questioning way of thinking becomes apparent, as a scholarly community 'gathers' around a given field of inquiry. If one thinks about an academic article as being akin to a work of art then Heidegger's thesis on art offers insight: 'the work erects a world, which in turn opens a space for man and things' (1999a, 
p. 141). The gathering of scholars discloses a world as the article comes into being, offering space for other readers and writers in other times and locales to gather towards further shelterings (Grierson, 2008, p. 61, 2015, p. 553).

To consider peer review as pedagogical does, however, raise the question of anonymity. What value does anonymity add? It seems illogical to suggest that the Heideggerian 'gathering' could be diminished if the reviewer's identity is known to the author or vice versa. One of the concerns of the anonymous peer reviewing process is that a reviewer can lose sight of the 'care' and 'trust' aspects of the role, thereby overlooking the duty to act in the best interests of an author and of the scholarly field. Likewise, an author may be affronted by a reviewer's comments and may even vent frustrations to the editor casting the whole process as negative. In the normative organisational model the life of an academic becomes functionalised as collegiality is reduced, too easily and too often, to instrumentalised ends. This new form of academic labour is exercised implicitly, and often, at the expense of an ethics of caring for others and for the academic labour itself, as peer reviewing is driven increasingly by performance measurements.

To be a competent peer reviewer obviously demands expert knowledge about the discipline in which the research is located. To see what is good in a submitted manuscript, to remember how much time and effort the authors have spent writing it, to tactfully diagnose and describe its major flaws, and skilfully suggest how these might be addressed: these skill sets are equally important, perhaps even more important, than expert status in disciplinary knowledge (Stewart, 2016). An expert peer reviewer couples their expert knowledge with the wisdom of humility, and a desire to serve based on deeply ethical commitment to one's field of research, which extends to its community. To find the wisdom of humility in peer reviewing as pedagogical work requires an ethos of care and trust, which places peer review in its rightful place in the core knowledge-building educational business of academic research.

On the other hand, functioning as a peer reviewer for academic journals improves writing skills and proficiency via exposure to other research papers, and cultivates connections with fellow specialists and scientific mentors. Reviewing provides a significant learning practice and a perspective of unpublished scholarship, assists in enhancing interaction and assessment, and offers constructive feedback that an academic is highly regarded and coactive in their sphere and furthers inner strength. These are noteworthy points to be returned to, in considering who is recruited and prepared to conduct peer reviews, and in what scholarly context.

\section{Difference, anonymity, and review}

Reviewing brings together a number of competing responsibilities for the reviewer. At the same time the reviewer is part of the ongoing process of delivering professional education to academics, he or she is also defending the status and academic prestige of the journal. So, the position is both about getting people in and keeping people out.

Keeping people out is part of the long history of learned societies. Haraway (1997) discusses the relationship between science and masculinity, a masculinity dependent upon a form of male chastity which was to be achieved only by the exclusion of women. Race and 
class also construct part of the exclusivity of science. More generally, inbreeding homophily, a raised compatibility between individuals with analogous attributes, is a sociological, population-level feature of human societies. Homophily can be found in interplays between editors, peer reviewers and contributors, but it can be detrimental to women and other minority scholars, whose academic endeavours may be disregarded, as a result of unconscious negative bias.

Double-anonymous review might be seen as a mechanism for shortcutting or bypassing this attitude towards those who don't fit in to the 'Learned Society's' conception of itself. Women and minorities may experience having to pass a higher bar to publication than men, and obscuring the name is a way of obscuring such factors (Pontille \& Torny, 2014). However, for anonymity to be preserved the writer should adopt the tone and style of the learned society, that is, middle class and masculinised. Using any form of ecriture feminine (Cixous, 1981) is likely to be penalised, even if there is no other indication of gender. Although it would be nice to think that this attitude is a thing in the past, reviewers can be intolerant of any writing that seems to transgress the Royal Society line: writing that is playful, personal, narrative, emotive or non-linear.

Double-anonymous reviewing is also becoming increasingly vulnerable to the ease with which the material being reviewed can be cross-referenced using search engines. This may suggest that single-anonymous reviewing is a preferable option, where the reviewers know the author, but the reviewers remain anonymous. Another alternative review model is two-stage publication and review, the first stage being a manuscript accepted as a discussion paper, subject to both open review and comment from the relevant academic community, while the second is subsequent publication of the article revised in light of the first stage process of review (Koop \& Pöschl, 2006).

Another possibility is review by known reviewers who do not know the identity of the authors. Elsevier conducted an experiment among reviewers of a number of journals in its stable, asking reviewers whether they would be willing to identify themselves, and be identified in published articles (Mehmani, 2016). Interestingly, some reviewers have taken up this idea so enthusiastically, that they now self-publish their review reports on their ORCID profiles. Relatedly, a BioMed Central (BMC) investigation compared the difference in quality between open peer review and anonymous review, finding a $5 \%$ improvement in the quality of open peer review reports over anonymous reviews (Winston, 2015).

As alluded to in the last section, among the advantages of reviewers being identified (either to the authors only or to the readers of the published article) is to prevent 'author bashing' by reviewers who write scathing, often hurtful, comments from behind the safety of the double-anonymous review process. Open review could also prevent property theft: that is, the reviewers stealing ideas from the article they review; or worse still, rejecting the article, yet pinching the ideas-an issue highlighted by Pontille and Torny (2014). Furthermore, published reviews have the benefit of enhancing an early researcher's publication profile, albeit in a relatively insignificant way.

Yet published reviews also run a number of risks. First, open reviews run the risk of being pallid and consensual. Undertaking a book review can be a double-edged sword if, for example, the reviewer has painstakingly read the text and remains unconvinced by the book's argument, but wishes to present a review of equanimity that does 
honour to the efforts of the author. The Elsevier experiment (Mehmani, 2016) did not necessarily find this, however-33\% of the editors in the trial suggested that open review provided more detailed and constructive reviews to authors.

Other risks to non-anonymous reviewing have come with the rise of social media. In a particular case of the journal Hypatia, the work of peer reviewers on an article by Tuvel (2017) was publicly undermined by a group of scholars and associate editors of the journal in an open letter (Winnubst, 2017). The article drew criticism for the way it described and compared the identity phenomena of trans-genderism and trans-racialism, and allegedly failed to engage with relevant work and discourse in relation to vulnerable, intersecting communities (Shotwell et al., 2017). Many scholars weighed into the debate using social media accounts, and exaggerated responses escalated, often alongside secondary and inaccurate reports of Tuvel's original argument. The associate editors' collective condemnation of the publication of Tuvel's paper and their claim it ought to be retracted and an apology issued arguably failed the Committee of Publication Ethics' Code of Ethics (Oliver, 2017; Singal, 2017). Eventually many members of the editorial board resigned in an effort to save the reputation of the journal (Weinberg, 2017). This academic tangle, largely underpinned by divided conceptions of philosophy, raised questions about the body of knowledge an author owes due deference particularly regarding citations for historically marginalised groups and the treatment of newer academics (Petkas, 2017). This example highlights the important role played by review process in the machinations of publication.

The gender proportion of reviewers should be comparable to that of published contributors of the same age. Yet as previous work (Gerstein \& Friedman, 2016; Layard, 2016; Machan, 2016; Popescu, 2016, 2017; Terry, 2016; Weede, 2016) indicates, women of all ages have fewer chances to participate in peer review. This may be caused by contributors and editors designating fewer women to review, or by women turning down requests more regularly than men. When potential reviewers pass up a request to review a paper, numerous journals solicit them to suggest alternative referees. An effective approach to assist in opposing gender unfairness in peer review might be the following: if authors are asked to recommend scholars, they should intentionally propose female fellows for the assignment, chiefly early-career individuals or low-ranking faculty members.

The BMC trial also considered the case of author-selected reviewers, finding that article acceptance was the more likely reviewer recommendation (Winston, 2015). This comes possibly as no surprise, and could indicate authors selecting reviewers likely to be sympathetic to their submission. Arguably, the practices places some pressure on reviewers to be more sympathetic. This impediment seems to be the polar opposite of the situation engendered by editorial policies that permit one or another of two anonymous reviewers veto power. From this perspective, the editor or editor-in-chief becomes no more than a clerical traffic police officer, waving some submissions through, unimpeded, diverting some to undertake necessary maintenance work before continuing, and bringing yet others to a dead stop.

Given such complexities, the double-anonymous system continues to be the preferred system (Pontille \& Torny, 2014). The next section focuses more deeply on the relationship between editor and reviewer. 


\section{Between editor and reviewer}

Academic publishing might usefully be described as going through a time of proliferation a feature of the contemporary perceived 'knowledge economy' that has particular demands on the functions of the academic in liaison with a range of actors in the academic publishing sphere. The changing relationship between editors and reviewers is a feature of this proliferation. In other words, this proliferation and its many influences have significant implications for contemporary relationships between editor and reviewer. For instance, we might see reviewers of journals in short supply, and hence editors of journals placed in a position where reviewing becomes a desperate need, in order to maintain the productivity of the journal. At the same time, where editors are also reviewers, they may become increasingly aware of the value of reciprocity at such times of short supply of reviewers. And of course, the respective authority of an editor or a journal adds complexity to this relationship-for instance where an editor's position in an institution or society gives them leverage when inviting colleagues or students to support a journal by engaging in the review process. In addition, publishing companies create incentives and conditions to support editors in recruitment of reviewers for what has traditionally been regarded as a presumed professional function in the life of the scholar.

These instances and the relationships that are evident in their enacting, are of interest inasmuch as they are power relationships between editors and reviewers. Various conceptualisations of power are relevant to an analysis of the relationships in the peer review process, including (but not limited to) the changing relationships between reviewer and editor. Conceptualised through their historical constructs, power relations in editor/ reviewer relationships lead us back to Foucault's (1980) work on power, and its workings in institutions. The traditional model of a juridical power construct claims that power belongs to someone, as it can be possessed and exercised by a class, people or an institution, and is productive in nature. Foucault's development of a power/knowledge analysis within his broader genealogical work is of interest here because of the ways in which the publishing relationship between editor and reviewer is a construction of self through various complex and dynamic power relations that produce a particular self knowledge (Foucault, 2003) - a knowledge that is institutionally bounded and governed but that, importantly to Foucault's thinking, is accepted by both editor and reviewer. The publishing companies, who exercise an institutional power over the relationship, engage in the production of relationships through a range of administrative and managerial functions.

In the first instance of power, the power in the peer review process appears to be held by the reviewer. As noted, reviewers are hard to find. The stronger the reputation of an academic, the more difficult it is to get them engaged in peer review, particularly within the current abundance of journals. Hence 'good' reviewers (or reviewers with good standing) are hard to find. If we consider the review process in terms of the selection of the reviewer, potential reviewers exercise their power not only in relation to making decisions about the paper being reviewed, but in relation to the ways they may or may not agree or decline the invitation to review a paper, and more recently by offering (or disregarding the request to offer) alternative reviewer names. Conversely, the more highly ranked the journal, the easier it is to persuade a reviewer to conduct a review.

The potential reviewer thus places the editor into a position of dependency, for the timely processing of publication, perhaps for the expertise available to conduct the 
review - since many micro fields of education can be particularly specialised-and for the time and energy spent by the editor in seeking, scoping and inviting further potential reviewers. Reviewing for an academic journal has limited value for academics seeking promotion, and reviewing activities receive limited recognition in terms of professional support or allocated time and resources. Reviewing a paper is then unsurprisingly one of those activities that can become sidelined, completed as an afterthought, or performed as an 'academic favour'.

The second instance to explore here is that of the editor's apparent advantage. As noted above, editors can rely on their contacts, students, and academic friendships to produce reviewers who are in some way obliged, rather than operating a seemingly impersonal system of aligning a paper to a reviewer with relevant expertise. The task of determining the quality of a review also lies within the editor's power. The idea of a 'good' or 'effective' review opens up the possible power relations in terms of the scope of an editor to determine what counts as good and/or effective reviewing, and whose opinion determines the fate of a submission. The editor can choose to disregard elements of the review that have been thoughtfully and constructively shared.

For the third instance, in supporting editors, publishing houses employ various strategies to attract reviewers who traditionally were not present in this process: access to free articles, vouchers, payments or places on editorial boards. Publishing companies also develop devices to support the editor in the nature of the approach to the reviewer. The example above, of asking a reviewer to name one or more alternate reviewers if they are unable to review, creates more than just an opportunity for the reviewer to exercise their will: the very system operates in a way that demands the reviewer to submit alternatives. At this point it is also important to recognise the role of publishing systems that deal with the management of the review process as well as, at times, elements of the production process, creating further uncertainty for the editor, on account of unknown administrative and production timeframes and processes.

Further complications in the relationships and power structures are caused by the subjectivity of reviewer decisions, highlighted in the 'best practice' type guidelines often offered by publishing houses to new reviewers. Further, while the lists of reviewers may be prized, perhaps even guarded, and often accompany the 'constant corporate mergers', the process also risks what Comer and Schwartz (2014) see as 'morally unacceptable' reviews and vituperative feedback, that 'erode an author's dignity by humiliating the author' (p. 141), again highlighting the dangerous ethical cusp on which the process is balanced.

Reviewer/editor relationships are highly complex and highly productive. Many positive relationships clearly develop between editors and reviewers, following the common theme of 'responsible academic citizenship'. At the same time, interactions between editors, reviewers and authors can become fraught with confrontations and tensions, all in the name of guarding and shaping the discipline through the act of academic peer review.

\section{Early career scholars and the labour of reviewing}

Considering the distinctive case of early career scholars, the processes, relationships, and labour of peer review may also represent rites of passage that indicate when a scholar has 
begun to be taken seriously as an expert in her discipline. Whilst the role is a voluntary addition to the intensified academic workload, from a Darwinian survivalist perspective, it enhances the researcher's public profile and tenured future while it provides a necessary service to the community. This labour of peer review is also a complex and subtle academic skill and potentially educative endeavour, as mentioned previously, both on the part of the reviewer and the author. It is time-consuming work with both benefits and risks.

It is worth placing the academic labour of peer review under further scrutiny in this context. While peer review is a marker of the science of academia that parallels the emergence of the modern university, there is no doubt that the conditions under which this form of academic labour is performed have altered. Peer review can no longer be confined to a geographical space absorbed into the temporal conditions of labour bound by the slowness of 'snail mail' and the hard copy manuscript. As with every aspect of academic life (encompassing writing, teaching, research and 'service'), technology and the changing nature of universities has involved an intensification of labour, in which a discrete working day shifts to one that is 'borderless', fluid and constant. Described by Adkins and Jokinen (2008) as the 'fourth shift', the conventional working day has been replaced by a stretched and flexible distribution of labour over $24 \mathrm{~h}$. Many workers are expected to work the standard 'day', but are now also expected to work outside of these times to ensure productivity and relevance across geography and timeframes.

Under such conditions, the intellectual labour of peer review for all academics, regardless of career stage and generation placement, needs to happen on laptops in airports, at night after busy days of meetings and teaching, and in the 'cracks' of the academic life lived in the context of visible outputs and measurable funding and research performance. Therein lies the paradox of the intensification of academic labour set in a context of increasing focus on research and publishing: peer review articles remain the gold standard of academic publishing and therefore contribute to the constant and incessant increase in the publication of scholarly articles (Adkins \& Dever, 2015). More and more reviewers are needed as a corollary of this acceleration of peer review publishing, meaning academics are being asked to review more articles in ever-diminishing timeframes and at a muchheightened pace, all in the context of a working life that is time-poor and constricted. As a further and final dimension that highlights the contradictions of outputs-driven academic labour, peer review is largely invisible and unrewarded-while positioned within a setting that awards all things visible and primarily the peer-review article. Such a situation makes conceivable 'predatory authors', who submit the same paper to several journals simultaneously, collect comments, and thus have their papers improved, and then aim for higher impact journals (Friedman, Friedman, \& Leverton, 2016; Lucas, 2016).

As demand for increased productivity from academics wishing to gain and secure employment may be accompanied by less mentorship, because the mentors are similarly under pressure to produce measurable research outputs, this may result in a lack of transparency in research processes and publishing rituals. Jackson and Stewart (2017, p. 105) note that nurturing junior scholars is deemed essential, but unless mentors have the time to do so, there may be a lack of transparency or explicit guidance on how to review an article or book, how to reply to reviewers' feedback, how to publish a highquality peer-reviewed article or write a book proposal, how to apply for funding, promotion, and so on. This lack of 'know how' is likely to adversely affect humanities 
disciplines such as philosophy in which single authored work is standard. In the sciences, in which multiple authored research is the norm, there are other academics with varying levels of experience and expertise a junior scholar can speak to and gain insight from as communal and collaborative efforts (ideally) lead to best practice. However, in discipline areas that generally see authors working alone, an early career researcher may be working it out by themselves, unless they have maintained a supportive relationship with their PhD Supervisor or established other mentoring relationships from which they can glean advice and access insight into the inner workings of the academic machine. For the independent scholar seeking a foothold in the academy, this is even more pronounced as they may also lack access to the support services and workshops run by research offices, scholars' centres, etc. Scholarship in isolation may result in a lack of best practice or supportive reviewing process (from both sides-as author or reviewer) if the people involved are lacking in experience or the opportunity to learn from the experience of others. As such, special issues such as EPAT's 'The editor interview project of the EPAT Editorial Development Group (EDG)' (Jackson \& Stewart, 2017) are rare and important resources.

\section{Conclusion}

The future of peer review is hard to predict, since it resides within the dynamic social, political-economic domain of publishing and information sharing. The age of digital reason has brought about a new logic of co-creation and co-production of knowledge and social goods, along with various novel non-academic models of peer review. These include virtual communities, 'smart mobs' (Rheingold, 1995, 2002) and various collaborative websites such as Wikipedia (Giles, 2005; Jandrić, 2010), which are worth further examination for their possible role in scholarship, knowledge production, and academic publishing. New technological advances also bring about new challenges. For instance, the Video Journal of Education and Pedagogy is unable to conduct anonymous peer review because video articles, as a rule of thumb, cannot be anonymised (Peters, Besley, et al., 2016). By and large, the new models and challenges of peer review have failed to make a significant impact in the cloistered world of mainstream academic publishing (Giles, 2005; Jandrić, 2010; Peters \& Jandrić, 2017). In this dynamic field, however, some of the many possibilities discussed herein may dramatically alter the research landscape of the future.

As discussed above contemporary academic publishing contains a large mix of diverse approaches to peer review. This is hardly a surprise, as 'the specific practices used to implement peer review-though they might seem hegemonic to the contemporary scholar slaving in his or her disciplinary silo-have, as noted, been in constant evolution since the early modern period' (Peters, Jandrić, et al., 2016, p. 1417). Thus, while the agglomeration of large academic publishers might have been expected to bring about some unification of the peer review processes, the mushrooming ecology of new independent journals and publishers gives rise to new understandings of peer review that counterbalance corporate trends. Advances in independent and corporate sectors are often inspired by principles and models developed outside of academia. We are only at the very beginning of the epoch of digital reason, and the outcome of these trends is hard to predict. 
Implications of this analysis might also be considered in relation to the training of new scholars and the monitoring of peer review processes. We have noted that while peer review can be educational for both authors and reviewers, this is not always the case, and negative experiences can be counterproductive. Training new scholars in handling and interpreting peer-review feedback they receive, and engaging in peer reviewing productively, are important in this context, as is finding ways to help new scholars understand risks related to their labour exploitation.

In regard to inequities in the peer-review process, academic outlets should consider gathering information at each phase of peer review to assist in determining the obstacles to publication that minority academics, such as women, confront. Author identity facts such as gender could be included in information on the numbers of manuscripts submitted to the journal, sent for review, sent again after revision, and appealed against, effectively or not, by rejected contributors. Observation of key-stage assessment information for lead contributors on approved and turned-down manuscripts may clarify gender and other forms of favouritism in publication (e.g. an unwillingness to appeal might be more prevalent among women and other minoritised groups). Evidence that such aspects are instrumental in biased results would facilitate their neutralisation (Overbaugh, 2017).

Finally, it is valuable for scholars to be responsive to the dynamic world of academic publishing, including continually thinking through their interactions and changing relationships with each other and with publishing companies, as they shape the way knowledge is produced and disseminated collaboratively and academic lives are experienced. In this article, we have intended to provide a foundation for future thinking on such vital issues.

\section{Disclosure statement}

No potential conflict of interest was reported by the authors.

\section{References}

Adkins, L., \& Dever, M. (2015). Academic labour-on-the-move. Australian Feminist Studies, 84(30), 105108. doi:10.1080/08164649.2015.1046303

Adkins, L., \& Jokinen, E. (2008). Gender, living and labour in the fourth shift. Nordic Journal of Feminist and Gender Research, (16)3, 138-149. doi:10.1080/08038740802300947

Barok, D., et al. Custodians.online (2015). In solidarity with Library Genesis and Sci-Hub. Retrieved from http://custodians.online/

Biagioli, M. (2002). From book censorship to academic peer review. Emergences: Journal for the Study of Media \& Composite Cultures, 12(1), 11-45.

Chapelle, F. H. (2014). The history and practice of peer review. Groundwater, 52(1), 1.

Cixous, H. (1981). The laugh of the medusa. In E. Marks \& I. de Courtivron (Eds.), New French feminisms (pp. 875-893). New York, NY: Schocken.

Comer, D. R., \& Schwartz, M. (2014). The problem of humiliation in peer review. Ethics \& Education, 9 (2), 141-156.

Fitzpatrick, K. (2011). Planned obsolescence: Publishing, technology, and the future of the academy. New York: NYU Press.

Foucault, M. (1980). Power/knowledge: Selected interviews and other writings (1972-1977). Brighton: Harvester Press. 
Foucault, M. (2003). Psychiatric Power: Lectures at the Collège de France 1973-1974 (G. Burchell, Ed.). New York, NY: Picador.

Friedman, H. H., Friedman, L. W., \& Leverton, C. (2016). Increase diversity to boost creativity and enhance problem solving. Psychosociological Issues in Human Resource Management, 4, 7-33.

Gerstein, M., \& Friedman, H. H. (2016). Rethinking higher education: Focusing on skills and competencies. Psychosociological Issues in Human Resource Management, 4, 104-121. doi:10.22381/ PIHRM4220165

Giles, J. (2005). Internet encyclopaedias go head to head. Nature, 438. Retrieved from https://www. nature.com/articles/438900a

Grierson, E. M. (2008). Heeding heidegger's way: Questions of the work of art. In V. Karalis (Ed.), Heidegger and the aesthetics of living (pp. 45-64). Newcastle: Cambridge Scholars Publishing.

Grierson, E. M. (2015). Activating aesthetics: Working with heidegger and bourdieu for engaged pedagogy. Educational Philosophy and Theory, 47(6), 546-562.

Haraway, D. J. (1997). Modest_witness@sSecond_millennium.FemaleMan(c)_meets_OncoMouse TM: Feminism and technoscience. London: Routledge.

Heidegger, M. (1999a). The origin of the work of Art. In D. Krell (Ed.), Basic writings: Martin heidegger (pp. 139-212). London: Routledge.

Heidegger, M. (1999b). The question concerning technology. In D. Krell (Ed.), Basic writings: Martin heidegger (pp. 343-363). London: Routledge.

Jackson, L., \& Stewart, G. (Eds.). (2017). Lifting the publishing curtain: The editor interview project of the EPAT Editorial Development Group (EDG). Educational Philosophy and Theory, 49(2), 105-111. doi:10.1080/00131857.2015.1069037

Jandrić, P. (2010). Wikipedia and education: Anarchist perspectives and virtual practices. Journal for Critical Education Policy Studies, 8(2), 48-73.

Jandrić, P. (2017). Learning in the age of the digital media. Rotterdam: Sense.

Koop, T., \& Pöschl, U. (2006). Systems: An open, two-stage peer-review journal. Nature. Retrieved from http://www.nature.com/nature/peerreview/debate/nature04988.html?foxtrotcallback=true

Layard, R. (2016). Why we should spend more on mental health. American Journal of Medical Research, 3, 188-206. doi:10.22381/AJMR3120167

Lucas, R. E. B. (2016). Integral migration in developing economies: An overview of recent evidence. Geopolitics, History, and International Relations, 8, 159-191.

Machan, T. R. (2016). The morality of gregarious egoism. Contemporary Readings in Law and Social Justice, 8, 7-29.

Mehmani, B. (2016). Is open peer review the way forward? Retrieved from https://www.elsevier.com/ reviewers-update/story/innovation-in-publishing/is-open-peer-review-the-way-forward

Oliver, K. (2017, May 8). If this is Feminism It's Been Hijacked by the thought police. The Philosophical Salon. Retrieved from http://thephilosophicalsalon.com/if-this-is-feminism-its-been-hijacked-bythe-thought-police/

Overbaugh, J. (2017). Gender bias: Track revisions and appeals. Nature, 543, 40. doi:10.1038/543040a

Peters, M. A., Besley, T., Jandrić, P., \& Bajić, M. (2016). Editorial interview. Video Journal of Education and Pedagogy, 1(2). Retrieved from http://videoeducationjournal.springeropen.com/articles/10. 1186/s40990-016-0006-z

Peters, M. A., \& Jandrić, P. (2017). The digital university: A dialogue and manifesto. New York, NY: Peter Lang.

Peters, M. A., Jandrić, P., Irwin, R., Locke, K., Devine, N., Heraud, R., ... Roberts, P. (2016). Toward a philosophy of academic publishing. Educational Philosophy and Theory, 48(14), 1401-1425.

Petkas, A. (2017, July 10). Why name a journal after Hypatia? Eidolon. Retrieved from https://eidolon. pub/why-name-a-journal-after-hypatia-a90b51d56f7c

Pontille, D., \& Torny, D. (2014). The blind shall see! The question of anonymity in journal peer review. Ada: A Journal of Gender, New Media, and Technology, no. 4.

Popescu, G. H. (2016). Gender, work, and wages: Patterns of female participation in the labor market. Journal of Self-Governance and Management Economics, 4, 128-134. doi:10.22381/JSME4120165

Popescu, G. H. (2017). The economics of e-learning production. Economics, Management, and Financial Markets, 12, 68-74. doi:10.22381/EMFM12120174 
Terry, A. (2016). Reconceptualizing gender: A historical perspective from structure to process and intersectionality. Journal of Research in Gender Studies, 6, 69-82. doi:10.22381/JRGS6220164

Rheingold, H. (1995). The virtual community: Homesteading on the electronic frontier. Cambridge, MA: MIT Press.

Rheingold, H. (2002). Smart mobs: The next social revolution. New York, NY: Basic Books.

Singal, J. (2017, May 2). This is what a modern-day witch hunt looks like. New York Magazine. Retrieved from http://nymag.com/daily/intelligencer/2017/05/transracialism-article-controversy. html

Tuvel, R. (2017). In defence of transracialism. Hypatia, 2(32), 263-278.

Stewart, G. (2016). Reviewing and ethics in the online academy (guest editorial). Educational Philosophy and Theory, 48(5), 437-442.

Shotwell, A., et al. (2017). Open letter to Hypatia. Gender Trender. Retrieved from https:// gendertrender.wordpress.com/

Weede, E. (2016). Geopolitics, institutions, and economics: On the rise and decline of civilizations. Geopolitics, History, and International Relations, 8, 177-220. doi:10.22381/GHIR8120168

Weinberg, J. (2017, July 24). Hypatia's Associate Editors Resign. Daily Nous. Retrieved from http:// dailynous.com/2017/07/24/hypatias-associate-editors-resign/

Winnubst, S. (2017, May 8). Why Tuvel's article so troubled its critics. The Chronicle Review of The Chronicle of Higher Education. Retrieved from http://www.chronicle.com/article/Why-Tuvel-sArticle-So/240029/

Winston, J. (2015). Open peer review could result in better quality of peer review. Retrieved from https://www.biomedcentral.com/about/press-centre/science-press-releases/30-09-2015

\section{Open review of first draft}

\section{Peter Roberts}

School of Educational Studies and Leadership, University of Canterbury, Christchurch, New Zealand

I have been asked to provide an open review of this manuscript, a process I support on ethical as well as academic grounds. While I have always defended the importance of peer review (see, for example, Roberts, 1999), I have long believed that any advantages associated with traditional double-blind reviewing are outweighed by the potential benefits of greater openness in the assessment of scholarly work. Subtle, complex dynamics of power, politics and personality are at play in any situation involving judgements of academic quality, whether the identities of the author(s), reviewers, or both, are known or not. As the article points out, however, '[o]ne of the concerns of the anonymous peer reviewing process is that a reviewer can lose sight of the 'care' and 'trust' aspects of the role, thereby overlooking the duty to act in the best interests of an author and of the scholarly field'. Anonymity for reviewers can provide a screen behind which nastiness, ignorance and prejudice may hide. An open process, where authors and reviewers are revealed to each other, can allow scholars to communicate in a more collegial manner, with feedback that is constructive, balanced and fair, without losing any of the rigour that peer review is expected to uphold.

The authors show that the antecedents to contemporary systems of peer review date back to the ancient Greeks. They raise some searching questions relating to gender and the evaluation of scholarly work. They point to some of the practical difficulties in securing 
good reviewers and they address aspects of the wider political economy of academic publishing. At the beginning of the second section in the article, the authors make the claim that peer review, rather than being 'an essentially judgemental exercise in humiliation', is better conceived as 'a form of pedagogy'. There is considerable scope for further worthwhile scholarship on this theme. In what ways, for whom, and under what conditions is the process pedagogical? How does peer review compare with other forms of pedagogy? Can it be miseducative or anti-educational? A promising direction for continuing inquiry is signalled near the end of the article with some insightful observations on the importance of, and constraints upon, mentoring in publishing and peer review. Intellectual mentoring, often conducted informally and with minimal institutional recognition, is frequently overlooked in discussions of teaching. The process of guiding others, directly or indirectly, as they acquire an understanding of the risks, rewards and responsibilities associated with submitting and reviewing scholarly work warrants ongoing philosophical reflection, and I would encourage the authors to build on the ideas advanced here in their subsequent collective writing endeavours.

More could also be said about the policy contexts that shape and structure contemporary scholarly practices. The introduction of performance-based research funding schemes, for example, has had a significant bearing on how and why academics undertake research, where and how often they seek to publish their findings, and, ultimately, how they see themselves (Roberts, 2006, 2013). Peer review, as the authors are aware, does not escape unchanged from the imposition of such schemes. There is only so much room in one article to investigate the different dimensions of a problem, but again, there is an opportunity here for philosophers of education to play an important role in analysing the ontological, epistemological, ethical, and educative consequences of new regimes of performance measurement. Focusing specifically and in more detail on the implications of performance-based research funding for practices of peer review would make a distinctive contribution to the existing critical literature in this area.

I commend the authors for their initiative in exploring fresh possibilities for collaboration in academic writing, and for their willingness to question the norms that govern scholarly and educational life.

\section{Disclosure statement}

No potential conflict of interest was reported by the author.

\section{References}

Roberts, P. (1999). Scholarly publishing, peer review and the internet. First Monday: The Peer-Reviewed Journal on the Internet, 4(4). Retrieved from http://ojphi.org/ojs/index.php/fm/article/view/661/ 576

Roberts, P. (2006). Performativity, measurement and research: A critique of performance-based research funding in New Zealand. In J. Ozga, T. Popkewitz, \& T. Seddon (Eds.), World yearbook of education 2006: Education research and policy (pp. 185-199). London: Routledge.

Roberts, P. (2013). Academic dystopia: Knowledge, performativity and tertiary education. Review of Education, Pedagogy, and Cultural Studies, 35(1), 27-43. 


\title{
Open review of first draft
}

\author{
Jānis (John) Ozoliņš
}

School of Philosophy, Australian Catholic University, Fitzroy, Australia

This article introduces a discussion of what is generaly an unsung, but vital part of academic work. It attracts no workload, but without it, academic research would be much the poorer. I refer to peer review, which is one of the central means whereby the quality of academic articles is judged. Other means will be through conference presentations, seminars and collaborative discussion of one's work with one's peers, all of which fail to appear in any metrics used to assess academic work because they are not sufficiently quantifiable. Though these broader mechanisms, which to some extent could be classed as peer review are not discussed in this article, questions in relation to the purpose of peer review, its weaknesses and, to a lesser extent, its strengths are. The importance of peer review lies in the observation that it is almost the sole means used in judging whether an article merits publication in a learned journal. In a metric obsessed higher education system where academics fear for their careers and reputations, let alone the prospects of promotion, peer review takes on special significance. This is because to have a paper published in a top tier journal can take up to four years, and so there is a considerable anxiety generated by the prospective outcomes of peer reviews. There is in this paper a number of places where this anxiety spills out into the discussion. This is to be expected, since an academic's sense of worth is very much tied up with the work that he or she has produced. Some of the issues raised in the discussion highlight this connection. Vituperative and disparaging reviews, gender bias, and theft of intellectual property are just some of issues raised. Crucially, though it cannot cover every issue, the paper stimulates reflection on the purposes of peer review, its value and how best it might be undertaken. In what follows, some comments are made on the various sections of the paper. These can be seen in two ways: (i) as a critical analysis of the quality of the paper, with some suggestions for changes - one of the traditional roles of a reviewer and (ii) an active engagement with the discussion.

In the first section, the idea that peer review has its origins in some form of peer administration of justice seems to be only distantly connected to peer review in the context of the publication of academic journal articles. There could be a point to be made that peer review is about the judgment of one's peers about one's work, but this, hopefully, is not about transgressions and hence punishment. Perhaps the point here is about peer review having a moral obligation to be conducted with fairness, where this is a matter of just treatment of the author's work. This should be brought out more clearly.

The following section raises the educational aspect of the peer review process, and proposes that there are positive ways in which it can be seen. Such a positive outlook in which the reviewers can be seen as engaged in a process of helping to improve and develop the ideas of a paper is to be welcomed, but it must be acknowledged but it is also quite possible that they will do a great deal to destroy the paper through negative and disparaging comments. This possibility is raised in other parts of the paper. Despite this, it is far better to focus on the positive aspects of the review process. There is in this section a noteworthy appeal to the collegial endeavour of the peer review process and a recognition of the place 
that the virtue of humility has in it. It helps to remind us as academics of our responsibility to each other, to our disciplines and to truth.

Some of the anxieties about the way in which peer review can function to diminish an academic's sense of worth are expressed in the section headed Difference, Anonymity and Review. The central premise is that peer review can be used to exclude as well as include people. There is certainly evidence of this and the first paragraph speculates that women face tougher scrutiny in the peer review process than men. The argument, however, is faulty. For example, the following statements are made: 'If women are presumed less gifted.... then their manuscripts may be more meticulously examined' and 'If reviewers use more stringent criteria for female-authored manuscripts then they go through more scrupulous evaluation.' The respective conclusions can only follow if the first two parts of the two hypotheticals are true. The first proposition is very clearly false and the second dubious at best. If there is gender bias against women, then the reasons need to be sought elsewhere.

Additional reasons are proposed in the following paragraphs. For instance that women are discriminated against through gender homophily and it is proposed that steps to be taken to limit this. Double blind review, however, it is contended here, may not obviate the problem of bias against women writers since the language used by the writer may not fit a particular paradigm and reviewers may be biased against certain female styles of writing. There is some truth in the idea that there are certain styles of writing for particular journals that someone submitting to that journal would be wise in following, but this will be true for both male and female writers. Whether it is the case that there is a feminine style of writing is highly contentious. The late Elizabeth Anscombe (19192001), probably one of a handful of truly great twentieth century philosophers, gave no comfort to those held that there was a feminist way of doing philosophy. This section would have been better framed by addressing the more general concerns of reviewing bias first, then highlighting the problems women in particular face. For instance, for all academics it would be wise in the process of planning a submission to a particular journal that an investigation be undertaken of the writing styles of articles published in that journal. It is also sensible to take a look at the list of reviewers for the journal, since a concentration of certain kinds of reviewers, such as heavily analytic and white, curmudgeonly males will mean that certain kinds of articles will be considered more favourably than others. Gender homophily is one type of homophily, but not the only kind, and authors should be aware of all of them.

Cosy and not so cosy relationships are addressed in what follows in the discussion of the relationships between reviewer and editor, which draws on Foucault's conception of power relations. These are variously exercised between reviewer and editor, editor and publisher, and reviewer and publisher. The question of soliciting good reviewers is complex, as the quality of the review is important in maintaining the quality of a journal. The standing of the reviewer in a particular field is also important, since this inevitably connected to the quality of the review. Journals will often publish the lists of those who act as reviewers as a statement of quality of the publication. The second last paragraph about commodification is much too short and what is said previously does not seem to warrant the assertion that power relations embody and perform the 'commodification of science and research'. It is also unclear why the process of peer review risks morally unacceptable reviews and vituperative feedback. That there are such occurrences 
may not be due to the system of peer review as such, but may be due to the moral failings of the reviewer.

The section on the early career researcher and the way in which work stretches to fill up most of an academic's working life certainly strikes a chord, especially as this reviewer was using some of his time in the airport to complete reviewing this article. There is something increasingly inhuman about the expectations that modern higher educational institutions have of academics. This section addresses some key issues that confront time poor academics. In particular, the problems that early career academics face in publishing in high quality journals and more importantly, maintaining an output that enables them to keep their jobs. Mentoring by established academics is one way forward, but they too are under the same pressure to keep producing first rate publications in highly ranked journals. The solution may be for academics to take back control of their institutions.

The concluding remarks select only one form discrimination, gender, as problematic in peer review, but it is not the only one. While it is helpful to point this out, issues of bias and discrimination affect all academics, whatever gender they are. For example, discrimination against work which does not conform to the usual norms of what constitutes academic writing, but which expresses new ideas would not be published. Most prestigious journals are keen to maintain their high ranking and editors would be hard pressed to accept something which lies outside the recognised forms of not only academic writing style but also research methodology. As a result, innovation and new ideas will be found in more experimental, less prestigious places. Such places, however, are no place for aspiring academics to publish their work if they want to thrive in the modern university.

There are a few typographical errors:

Page 1 para 2 'academic' is misspelled and so is 'practised'. ('s' not ' $c$ ').

Page 1 line 5 up Spelling of Henry Oldenburg's surname. Not spelt with an ' $h$ ' at the end. Page 10 para 2 line 2 'peer review'. 'r' missing.

\section{Disclosure statement}

No potential conflict of interest was reported by the author.

\section{Second open review following revision}

Jānis (John) Ozoliņ̌̌

School of Philosophy, Australian Catholic University, Fitzroy, Australia

It is evident that the authors have responded to the critical points made by my review. The section, Difference, anonymity and review, which I had criticized for poor argument, has been significantly revised in line with the comments made. Significant portions have been deleted. Certainly the faulty argument has been corrected by being removed, but perhaps some part of a more general point along with it. That there is homophily is 
undoubtedly true, and it would not be beyond the realms of possibility that some of it is gender homophily, amongst other kinds. Those of race and class come out a little more clearly than previously. The section has been streamlined and the points about various kinds of bias brought out in the sorry story about the Hypatia article that was submitted to open review. It is stronger for the changes.

The following section, dealing with the relationships between editors and reviewers has also been modified in the light of comments made in the review. The changes, it seems to me, have improved the overall flow of the argument, and the claim about the relationship between power relations and commodification has been omitted.

The conclusion has also been modified to take into account the suggestions made in my review.

The article has been improved through the changes made in the light of the suggestions made by the reviewers. I look forward to seeing it published.

9th March 2018.

For Biographical notes on reviewers see.

http://editorscollective.org.nz/.

\section{Editor's Note.}

The Open Review of Educational Research is a blind peer review journal. I have made an exception in the case because it is an article that questions peer review and has experimented with the process of open review that involves publishing the contents of the review as part of the article. I want to raise potential conflict of interests to allay any fears that matters have been properly and professionally dealt with. It happens that I am also one of the authors of this collective paper although not the lead author. It is important to make these aspects public. Peer review certainly is not fool-proof but it is one of the best means for preserving objectivity and containing bias, for protecting the author against undue ideological influence, and for making sure that good quality papers are published irrespective of their source. In this case the open peer review process mentions both the reviewers and makes public their assessment of the article.

\section{Disclosure statement}

No potential conflict of interest was reported by the author.

\section{Notes on contributors}

Liz Jackson is Associate Professor of Education at the University of Hong Kong. She is also the Director of the Comparative Education Research Centre and Vice-President of the Philosophy of Education Society of Australasia. Her research interests are in philosophy of education and global studies of education with a focus on cross-cultural, multicultural, and moral and civic education.

The biographies of all the other authors can be found at: http://editorscollective.org.nz/membership/ 